Supplement of

\title{
Wintertime aerosol chemical composition, volatility, and spatial variability in the greater London area
}

\section{Xu et al.}

Correspondence to: N. L. Ng (ng@ chbe.gatech.edu)

The copyright of individual parts of the supplement might differ from the CC-BY 3.0 licence. 
Fig. S1. (a) Meteorological conditions (i.e., wind speed, relative humidity, and temperature) at the Detling site. (b) Wind rose plot. $0^{\circ}, 90^{\circ}, 180^{\circ}$, and $270^{\circ}$ represent north, east, south, and west, respectively. The radial scale represents the relative frequency of the wind direction.

Fig. S2. Schematic of the instrumental setup. SP2 represents single particle soot photometer. SPAMS represents soot-particle aerosol mass spectrometer. HR-ToF-AMS represents highresolution time-of-flight aerosol mass spectrometer. SMPS represents scanning mobility particle sizer.

Fig. S3. Particle mass loss within the thermal denuder as a function of heating temperature.

Fig. S4. Diagnostic plots of the unconstrained PMF analysis on the ambient data (i.e., PMFambient). (1) Q/Qexp as a function of number of factors; (2) Q/Qexp as a function of FPEAK for the solution with optimal number of factors; (3) mass fraction of OA factors as a function of FPEAK; (4) correlations of time series and mass spectra among OA factors; (5) the distribution of scaled residuals for each $\mathrm{m} / \mathrm{z}$; (6) the time series of the measured and the reconstructed organic mass; (7) time series of variations of the least-square-fit residual (= measured - reconstructed); (8) the time series of $\mathrm{Q} / \mathrm{Q}_{\exp }$; (9) the $\mathrm{Q} / \mathrm{Q}_{\exp }$ values as a function of $\mathrm{m} / \mathrm{z}$.

Fig. S5. (a) Time series of Q/Qexp for both 3-factor solution and 4-factor solution of PMFambient. (b) $\mathrm{Q} / \mathrm{Q} \exp$ values as a function of $m / \mathrm{z}$ for both 3-factor solution and 4-factor solution. (c) Mass spectra of the 4-factor solution. (d) Comparison between 3-factor solution and 4-factor solution in terms of the time series of OA factors. OOA_4fac represents the sum of MO-OOA and LO-OOA in the 4-factor solution. Increasing from 3-factor solution to 4-factor solution only has small effects on the time series of Q/Q exp. From 3-factor solution to 4-factor solution, the OOA factor (in 3-factor solution) splits into two OOA factors (in 4-factor solution). The time series of SFOA and HOA remain almost untouched.

Fig. S6. Three-factor solution of the unconstrained PMF analysis on the combined ambient and thermally-denuded OA spectra (i.e., PMFambient+TD). The “mixing” behavior of OA factors occur. Firstly, factor 2 has similar fragmentation patterns as HOA, but factor 2 also has substantial signal at $\mathrm{C}_{2} \mathrm{H}_{4} \mathrm{O}_{2}{ }^{+}(\mathrm{m} / \mathrm{z}$ 60, often used as a tracer marker for SFOA). Secondly, factor 1 from PMFambient+TD has similar time series as SFOA from PMFambient, but similar mass spectrum as OOA from PMFambient. In contrast, factor 3 from PMFambient+TD has similar time series as OOA from PMFambient, but similar mass spectrum as SFOA from PMFambient.

Fig. S7. Four-factor solution of the unconstrained PMF analysis on the combined ambient and thermally-denuded OA spectra (i.e., PMFambient+TD). The mass loading of the most oxygenated OA factor (i.e., green) is occasionally higher in the TD runs compared to the preceding and succeeding bypass runs.

Fig. S8. Sensitivity test on the effects of constrain tightness (i.e., varying $a$ value) for PMF analysis using ME-2 solver on $120^{\circ} \mathrm{C}$ organic data (i.e. ME-2120C). The anchor profiles of three OA factors are obtained from unconstrained PMF analysis on the ambient data (i.e. PMFambient). While the OOA mass spectrum is not constrained, the mass spectra of HOA and SFOA are constrained with varying $a$ value $(0-0.1)$. (a) $\mathrm{Q} / \mathrm{Q}_{\exp }$ as a function of $a$ value. (b) The mass concentration of three 
OA factors as a function of $a$ value. (c) The mass spectra of three OA factors by using different $a$ value.

Fig. S9. Sensitivity test on the effects of constrain tightness (i.e., varying $a$ value) for PMF analysis using ME-2 solver on $250^{\circ} \mathrm{C}$ organic data (i.e. ME-2250C). The anchor profiles of three OA factors are obtained from unconstrained PMF analysis on the ambient data (i.e. PMFambient). While the OOA mass spectrum is not constrained, the mass spectra of HOA and SFOA are constrained with varying $a$ value $(0-0.1)$. (a) $\mathrm{Q} / \mathrm{Q} \exp$ as a function of $a$ value. (b) The mass concentration of three OA factors as a function of $a$ value. (c) The mass spectra of three OA factors by using different $a$ value.

Fig. S10. Mass spectra of OOA factor resolved from PMF analysis on organics of bypass line (using PMF2 solver), $120^{\circ} \mathrm{C}$ (using ME-2 solver), and $250^{\circ} \mathrm{C}$ (using ME-2 solver).

Fig. S11. The designated regions for the origin of air masses in the NAME model.

Fig. S12. Diurnal trend of $\mathrm{NO}^{+} / \mathrm{NO}_{2}{ }^{+}$ratio. The $\mathrm{NO}^{+} / \mathrm{NO}_{2}{ }^{+}$ratio of ammonium nitrate was determined from the ionization efficiency calibrations.

Fig. S13. Diurnal trends of non-refractory species and OA factors for both NK and Detling sites.

Fig. S14. The average concentrations of sulfate at the NK and Detling sites when air masses come from westerly and easterly. The error bars indicate the standard error.

Fig. S15. The intensity of high $\mathrm{m} / \mathrm{z}$ (i.e., from 100 to $180 \mathrm{amu}$ ) for different TD temperatures. The intensities at all $\mathrm{m} / \mathrm{z}^{\prime} \mathrm{s}$ decrease with increasing TD temperature, which suggests no oligomer formation in the TD.

Fig. S16. O:C enhancement (i.e., ratio of TD line O:C to bypass line O:C) as a function of bypass line O:C based on Aiken et al. (2008).

Table S1. The campaign-average collection efficiency of HR-ToF-AMS calculated based on composition dependent algorithm (i.e., CDCE) and comparison with collocated SMPS measurement (SMPS-CE). The sensitivity of black carbon density on SMPS-CE is tested. 
Fig. S1
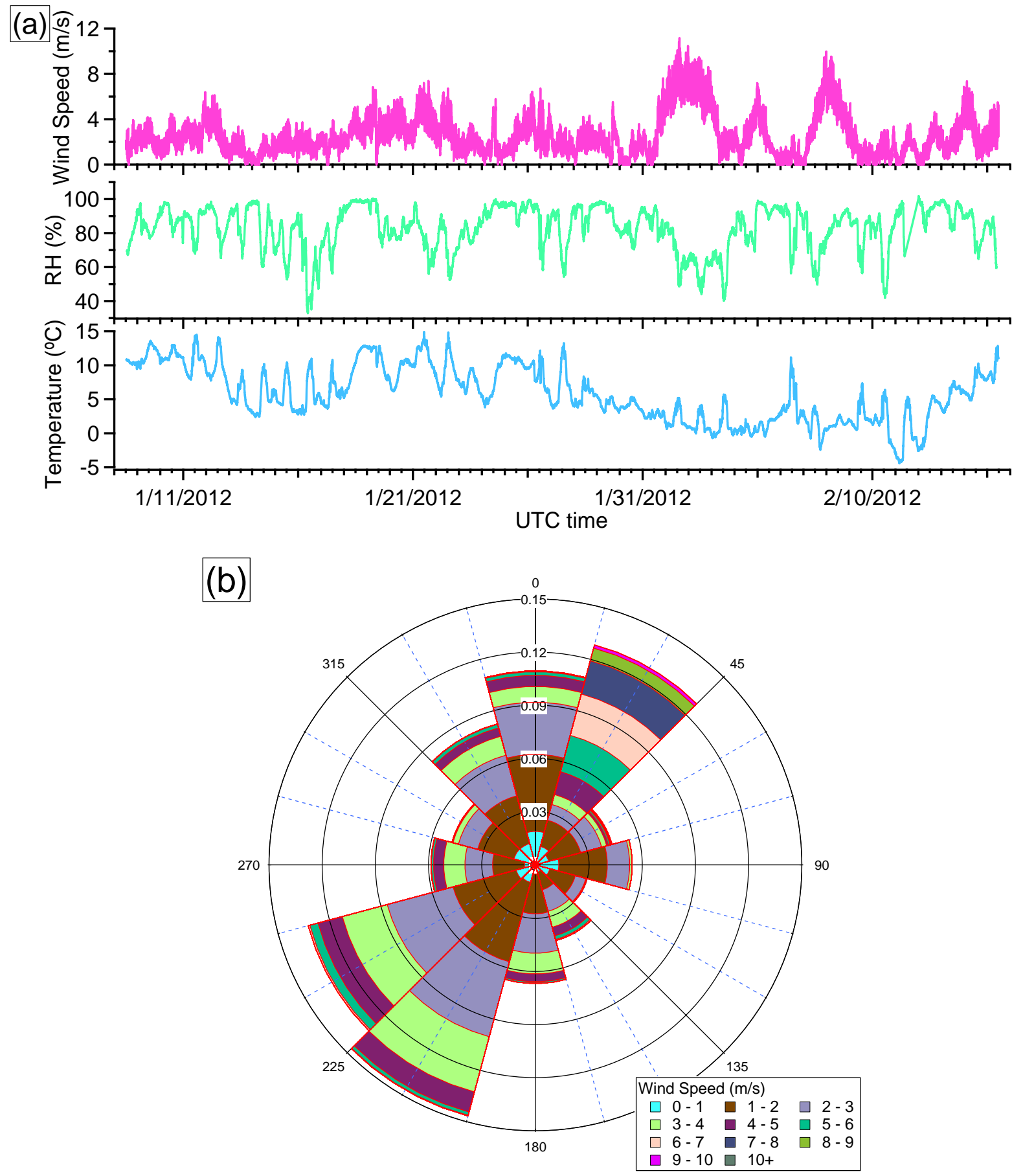
Fig. S2

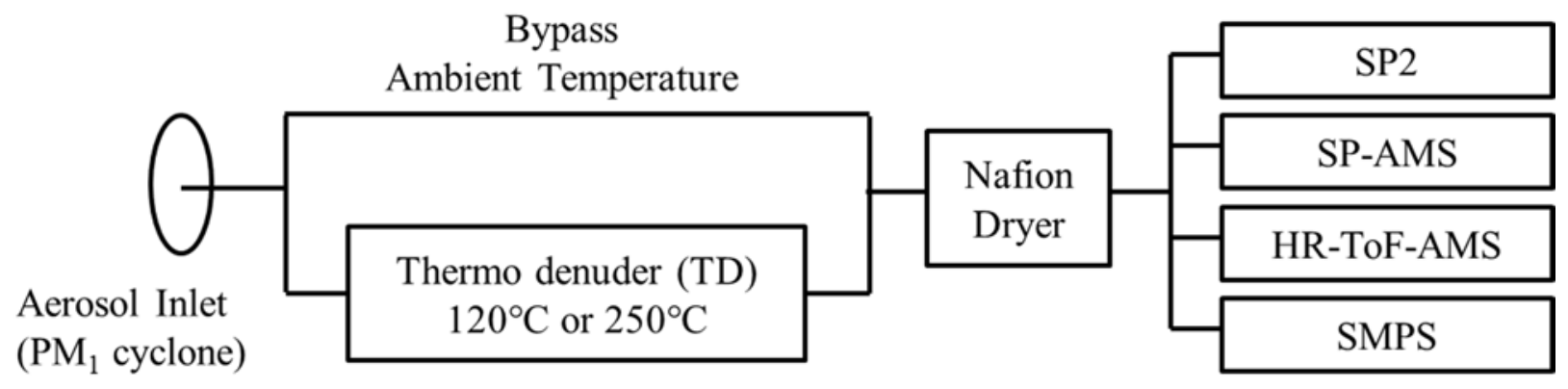


Fig. S3

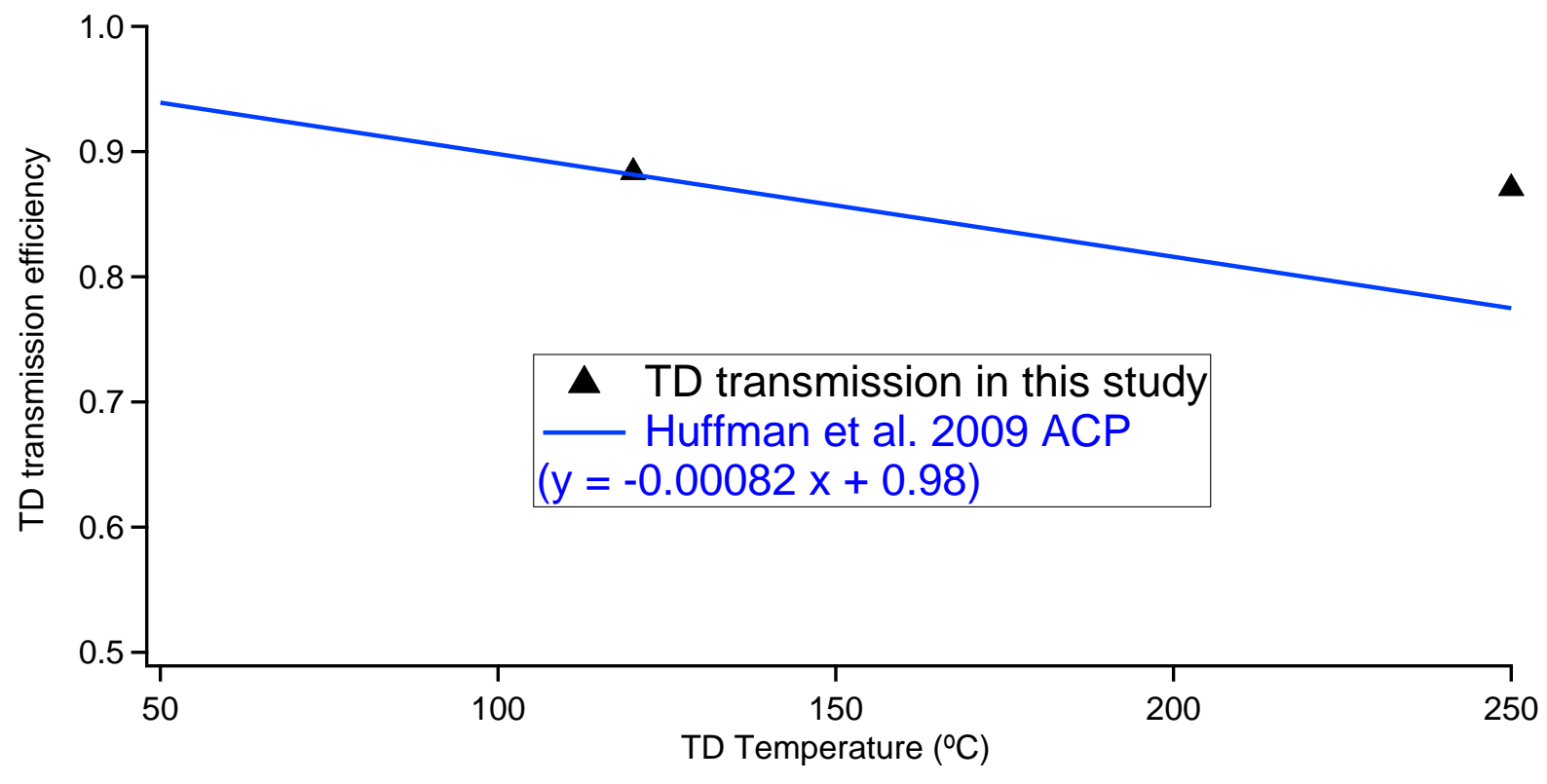


Fig. S4
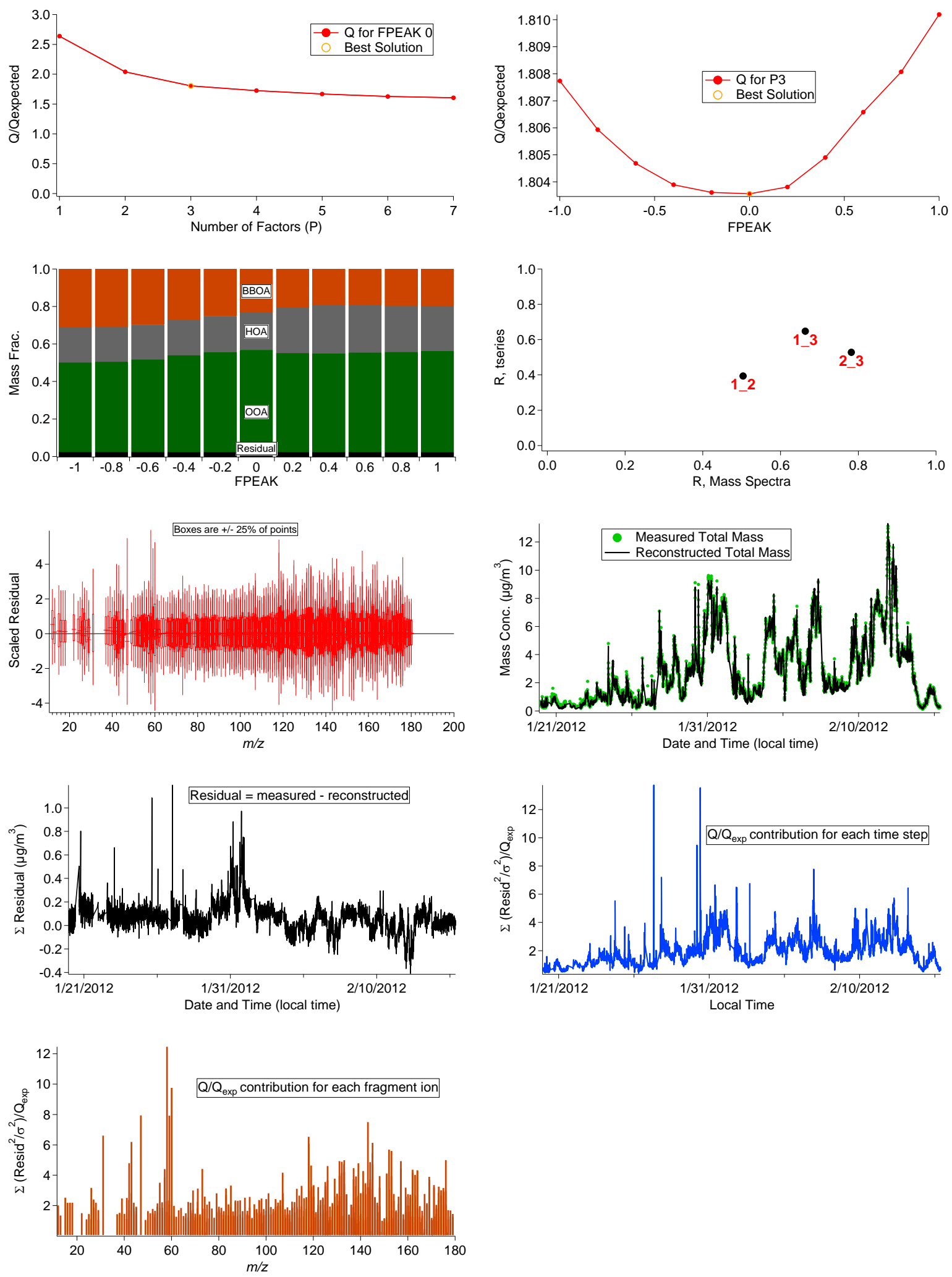
Fig. S5
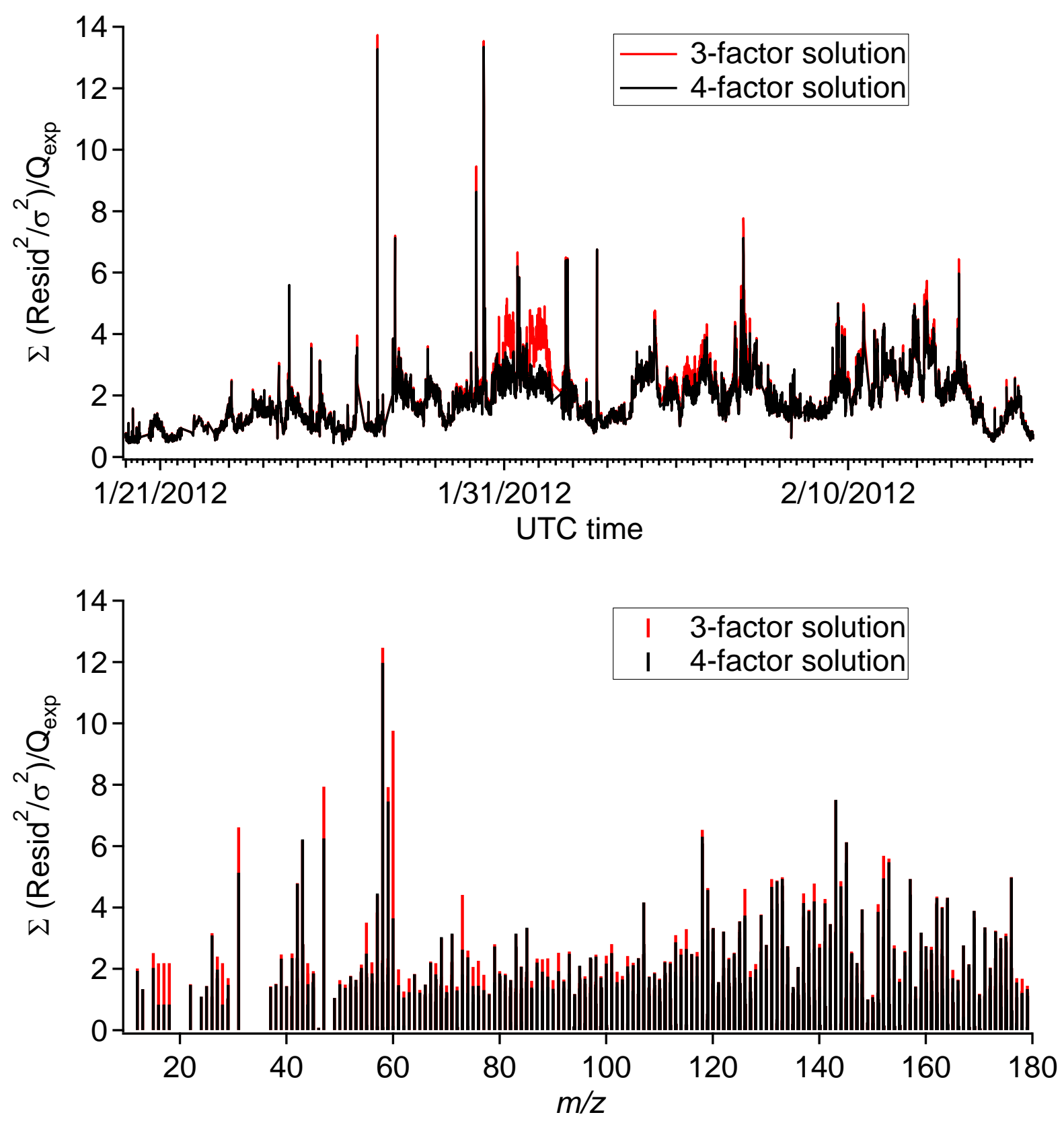
Fig. S5 continued
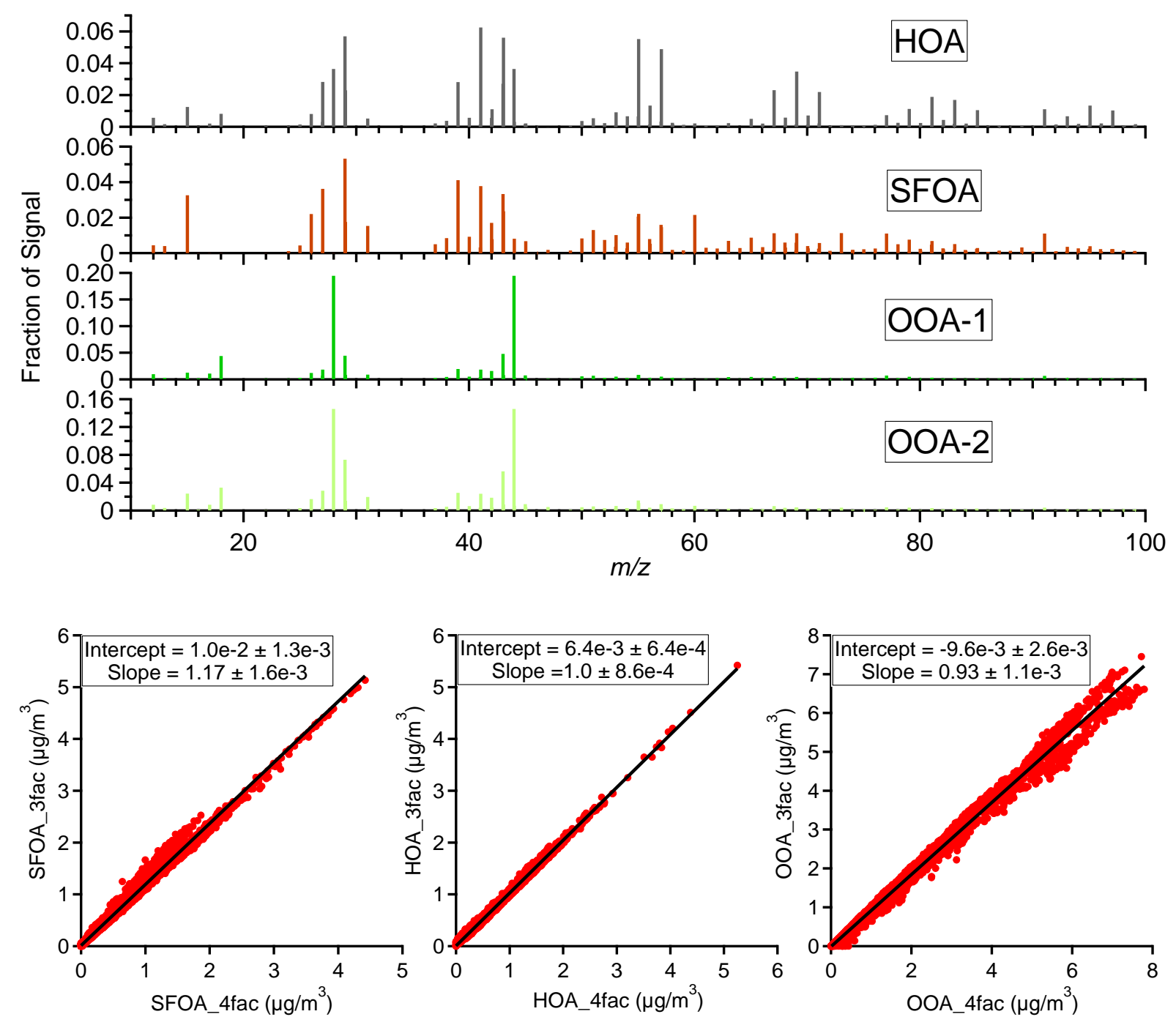
Fig. S6
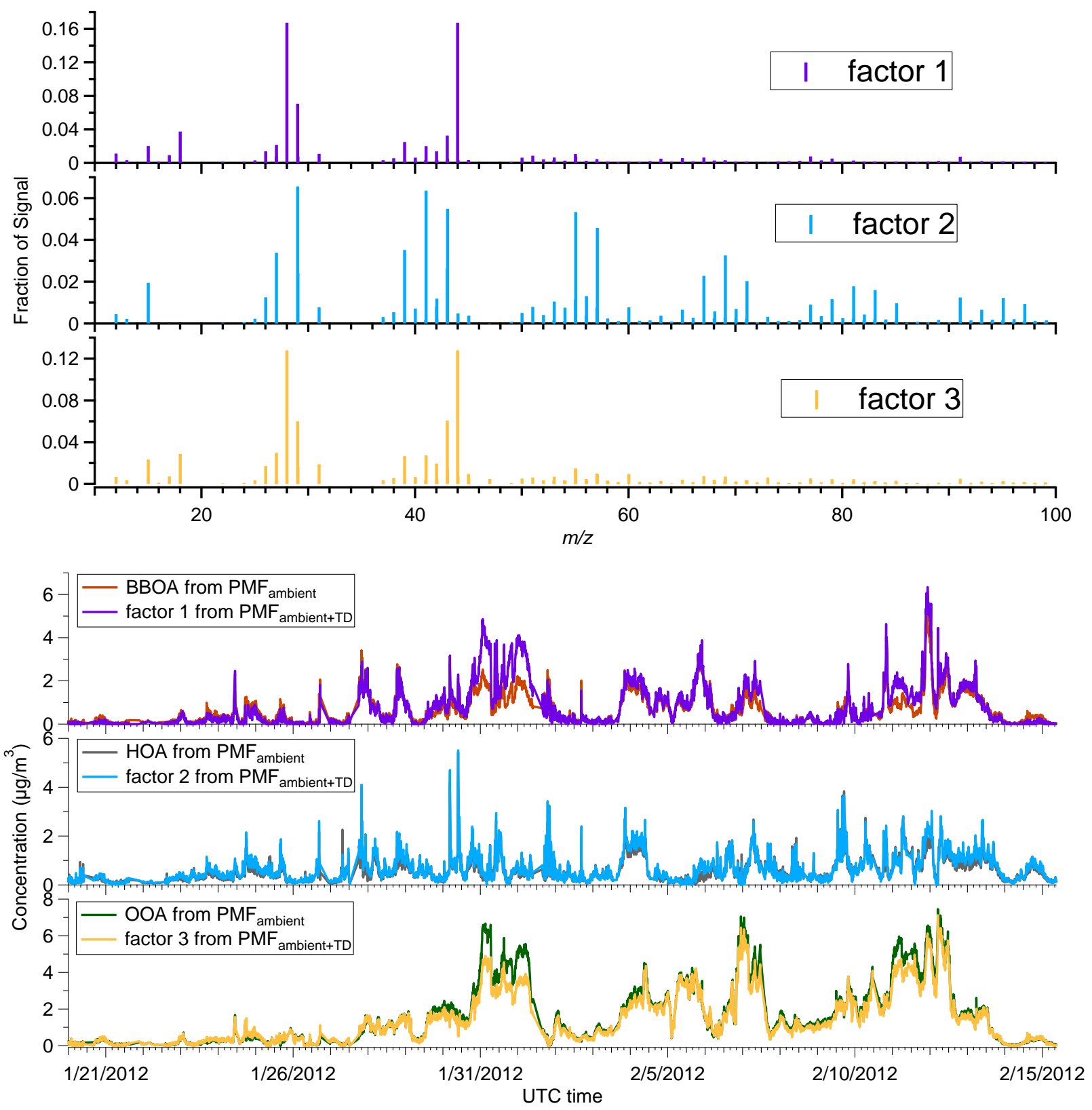
Fig. S7
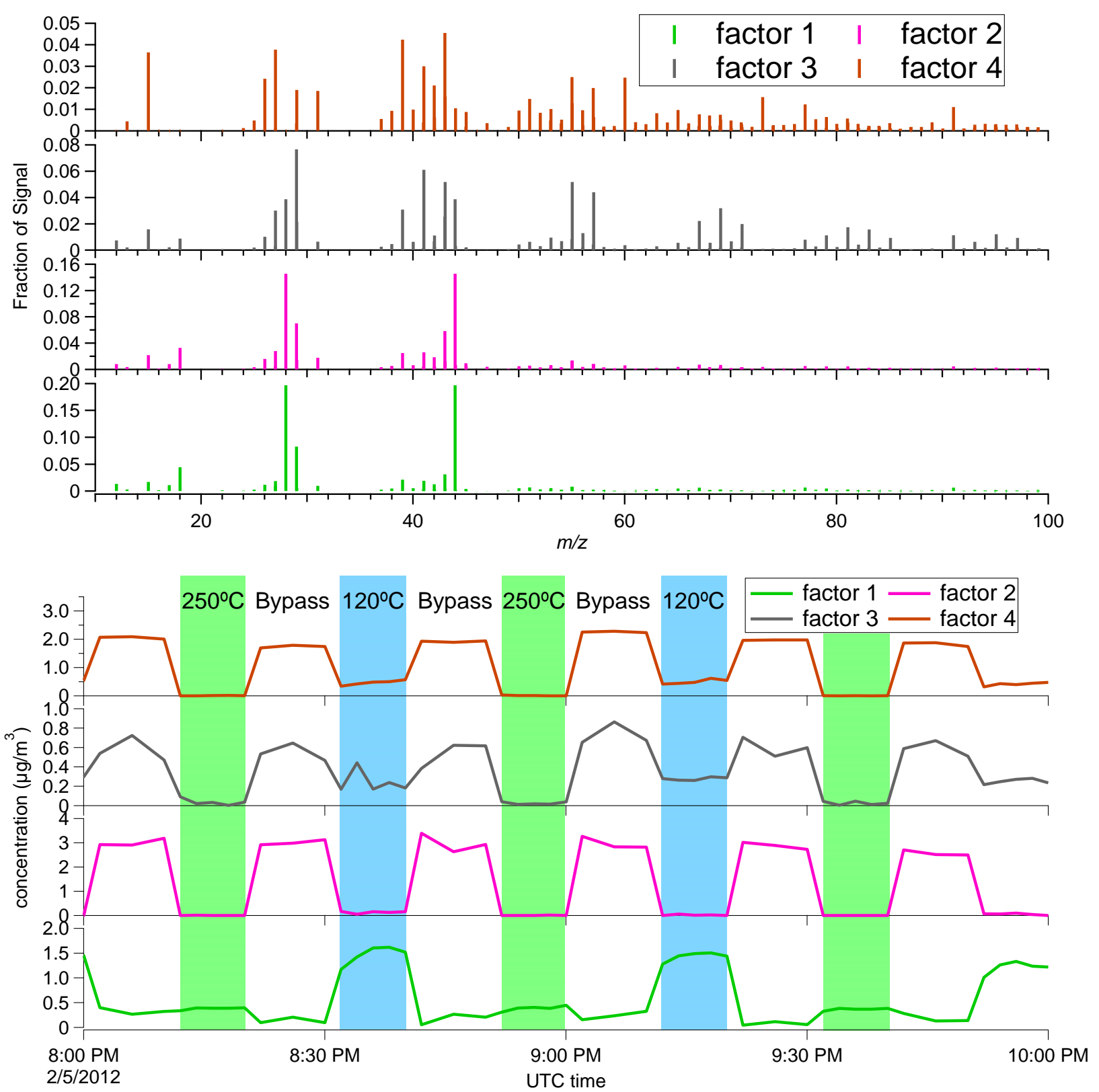
Fig. S8
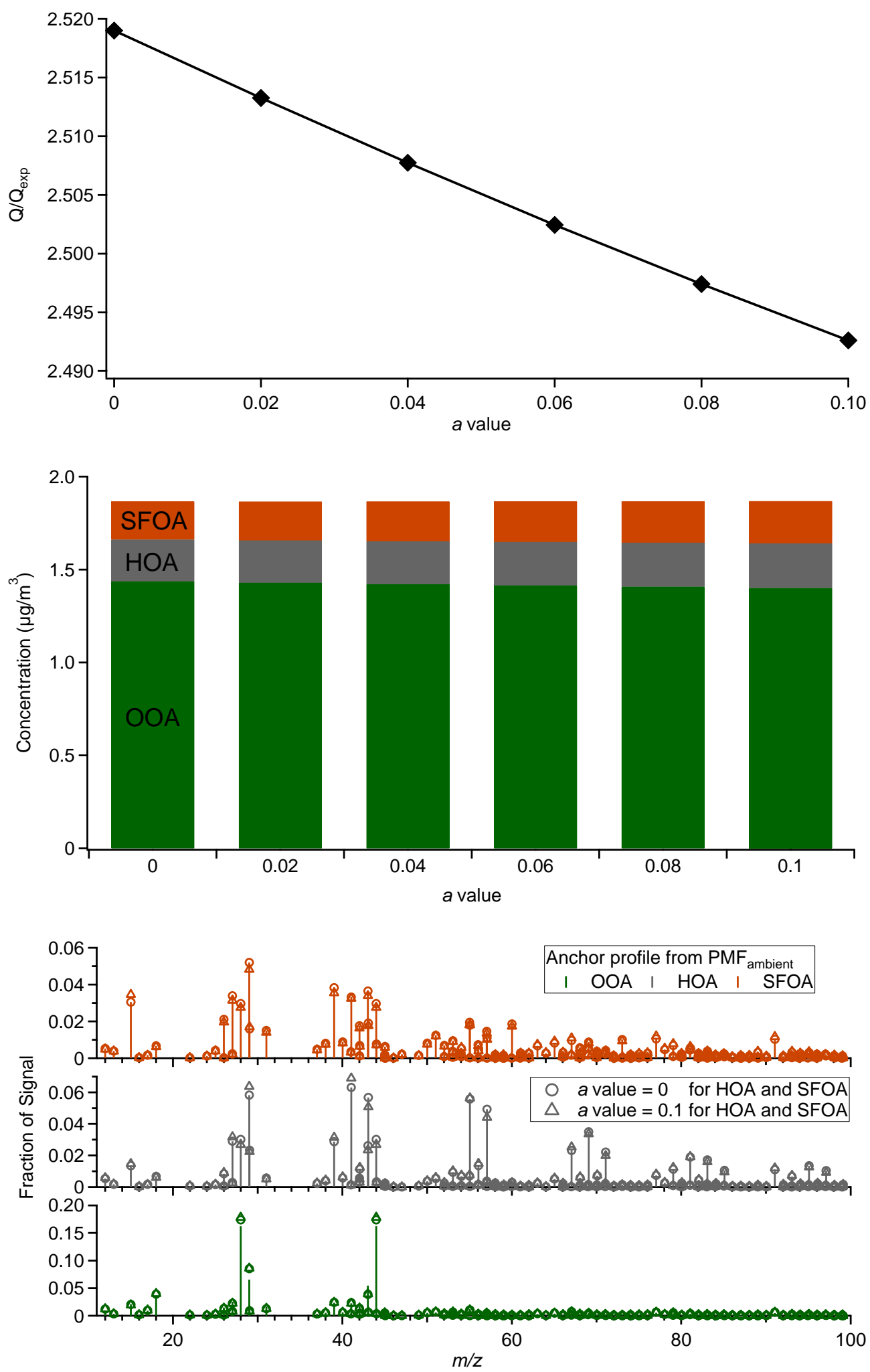
Fig. S9
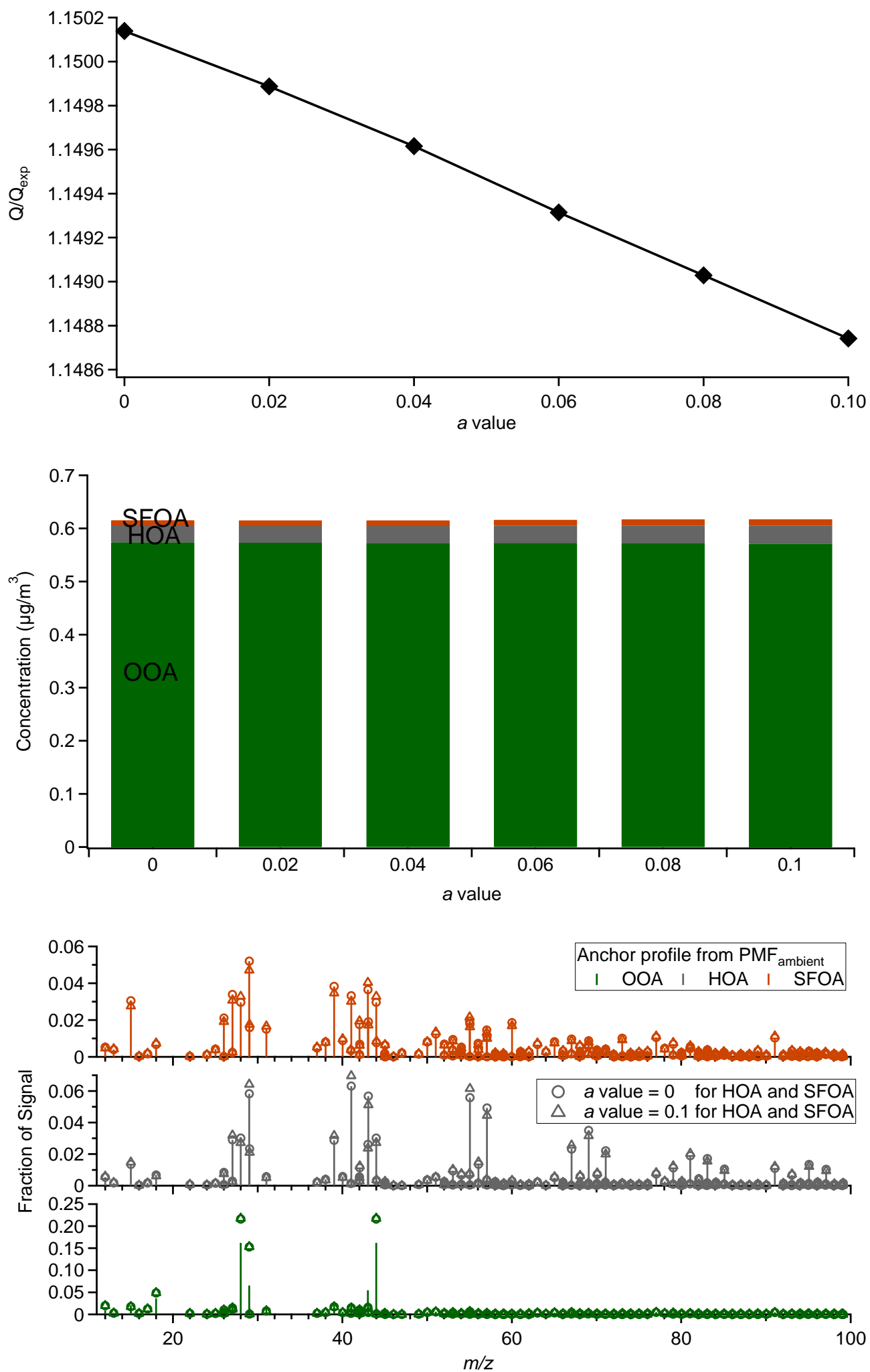
Fig. S10

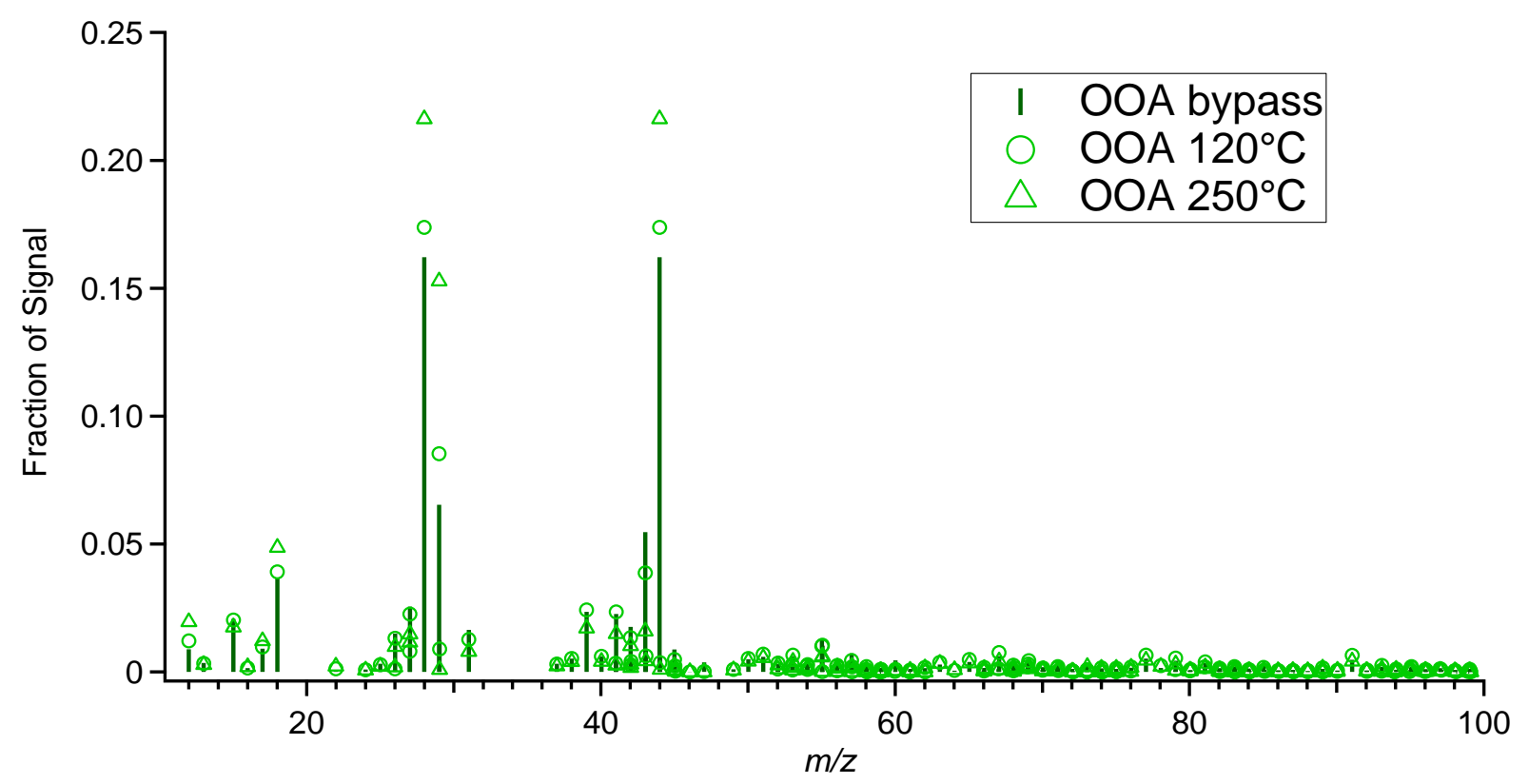


Fig. S11

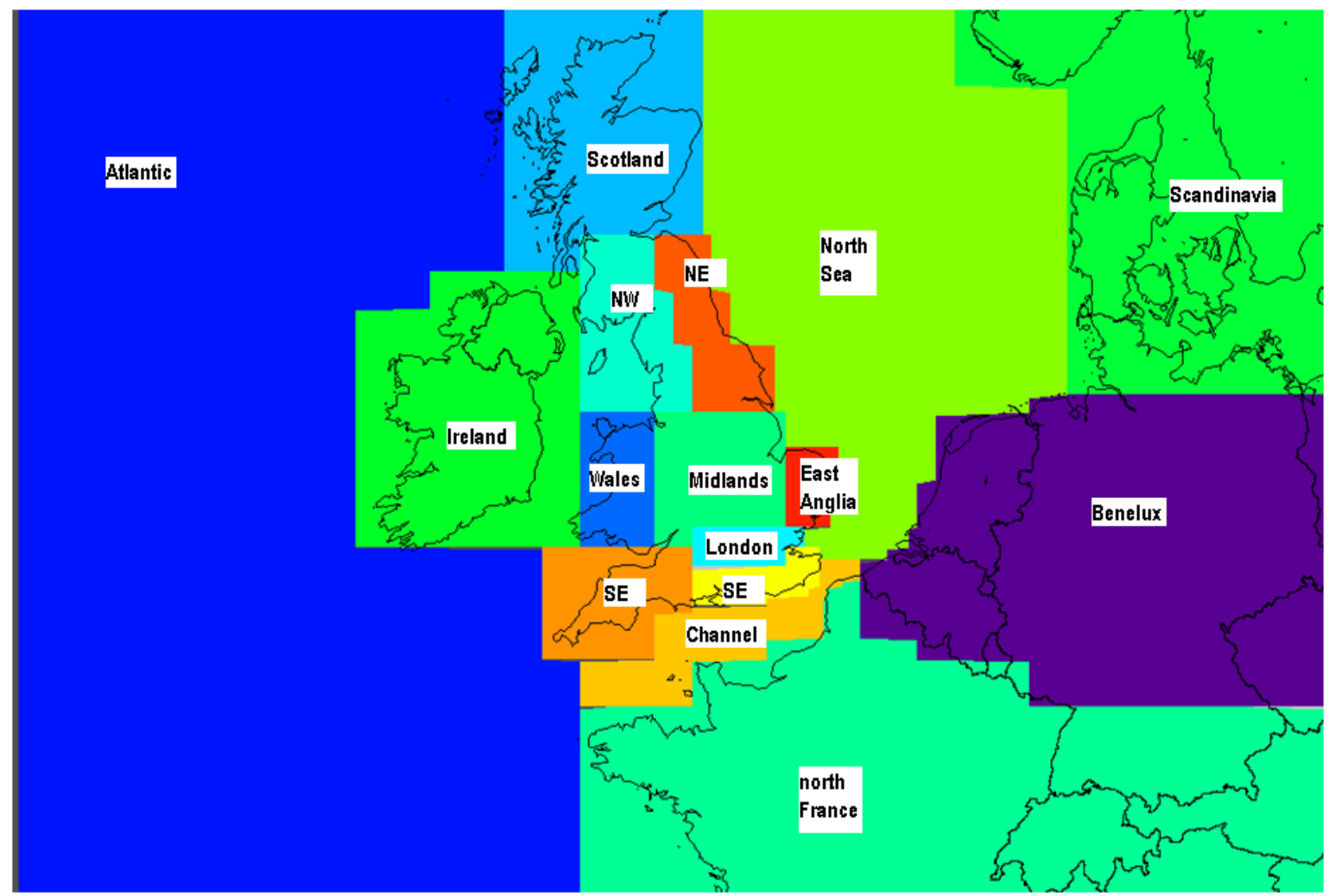


Fig. S12

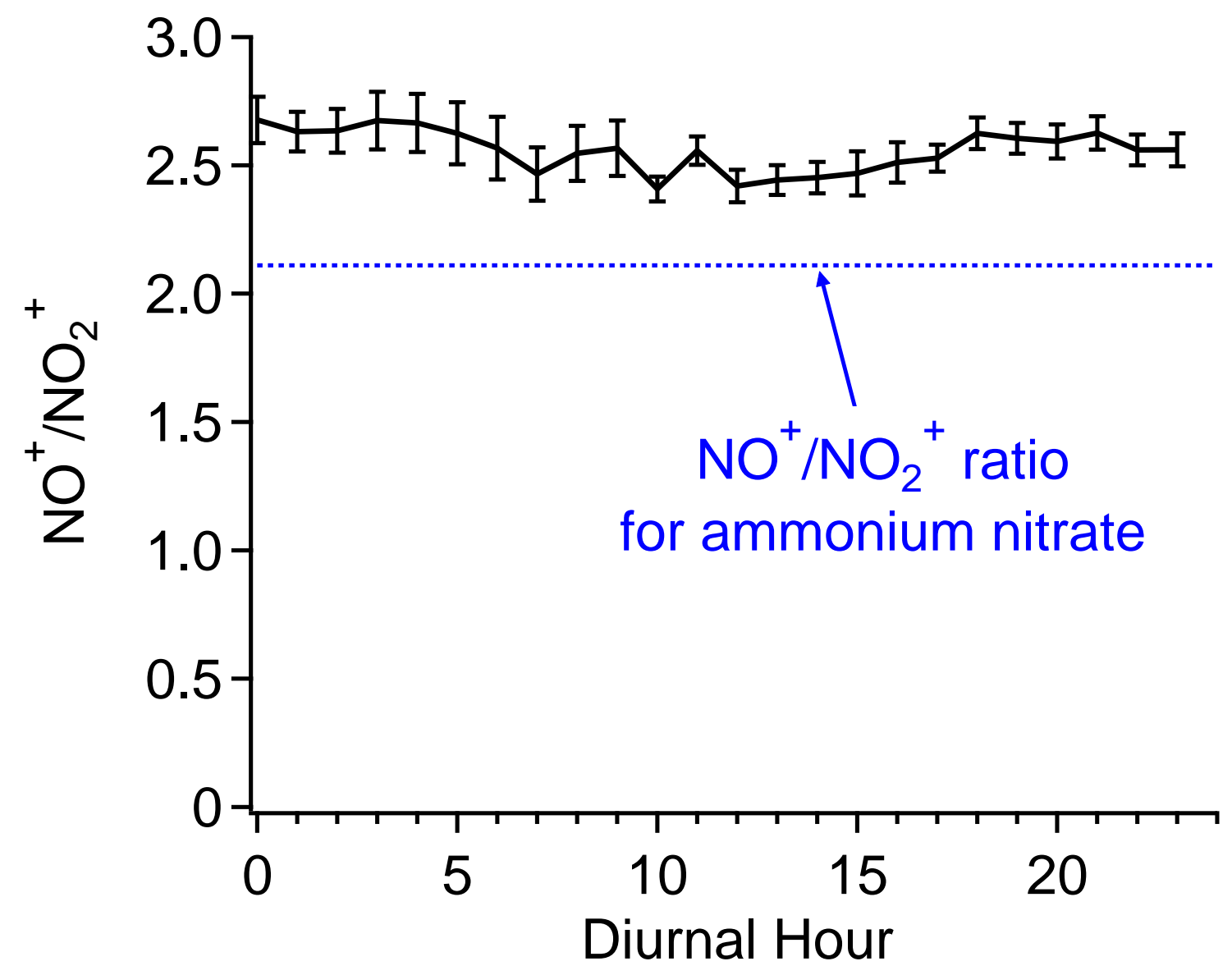


Fig. S13
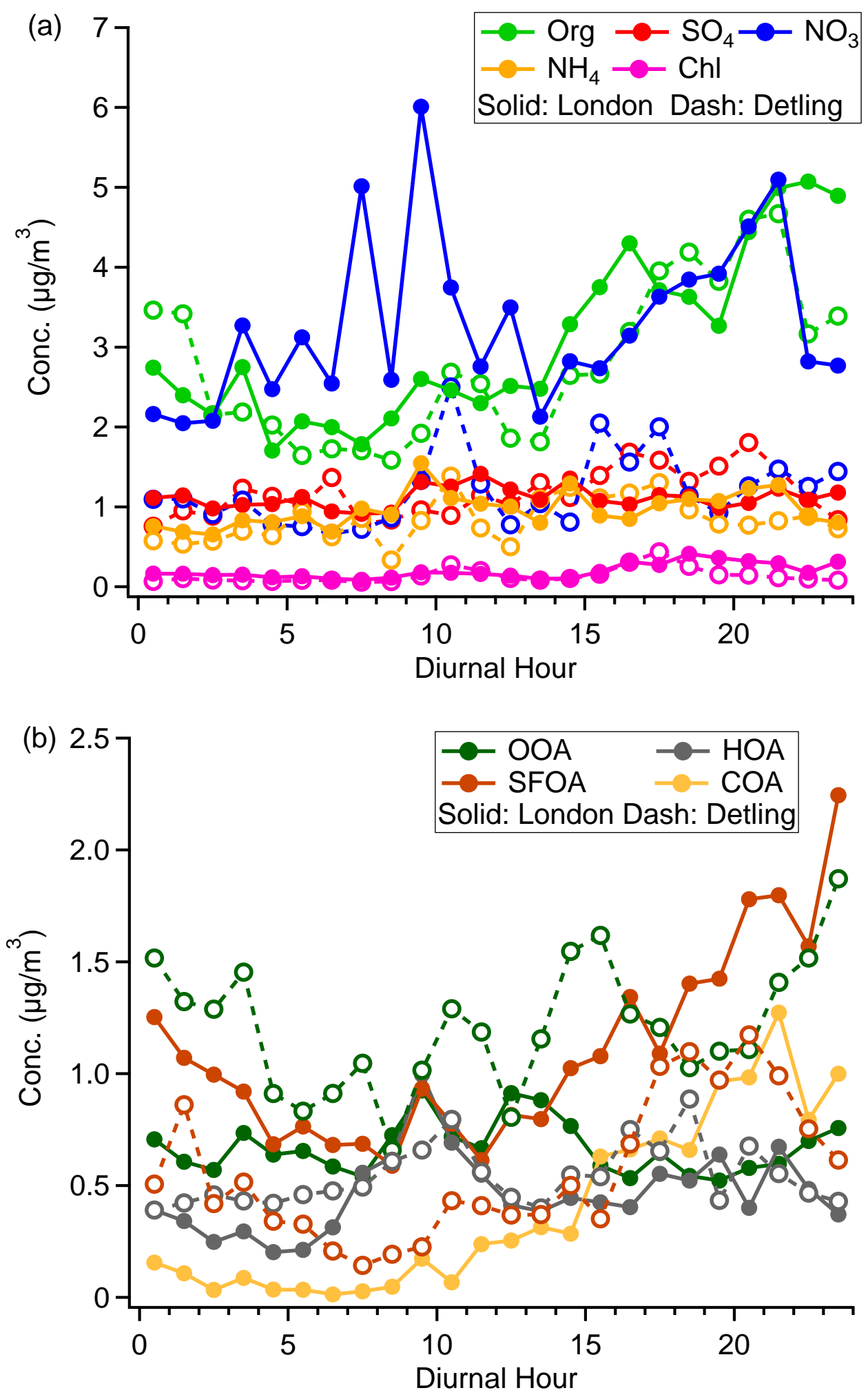
Fig. S14

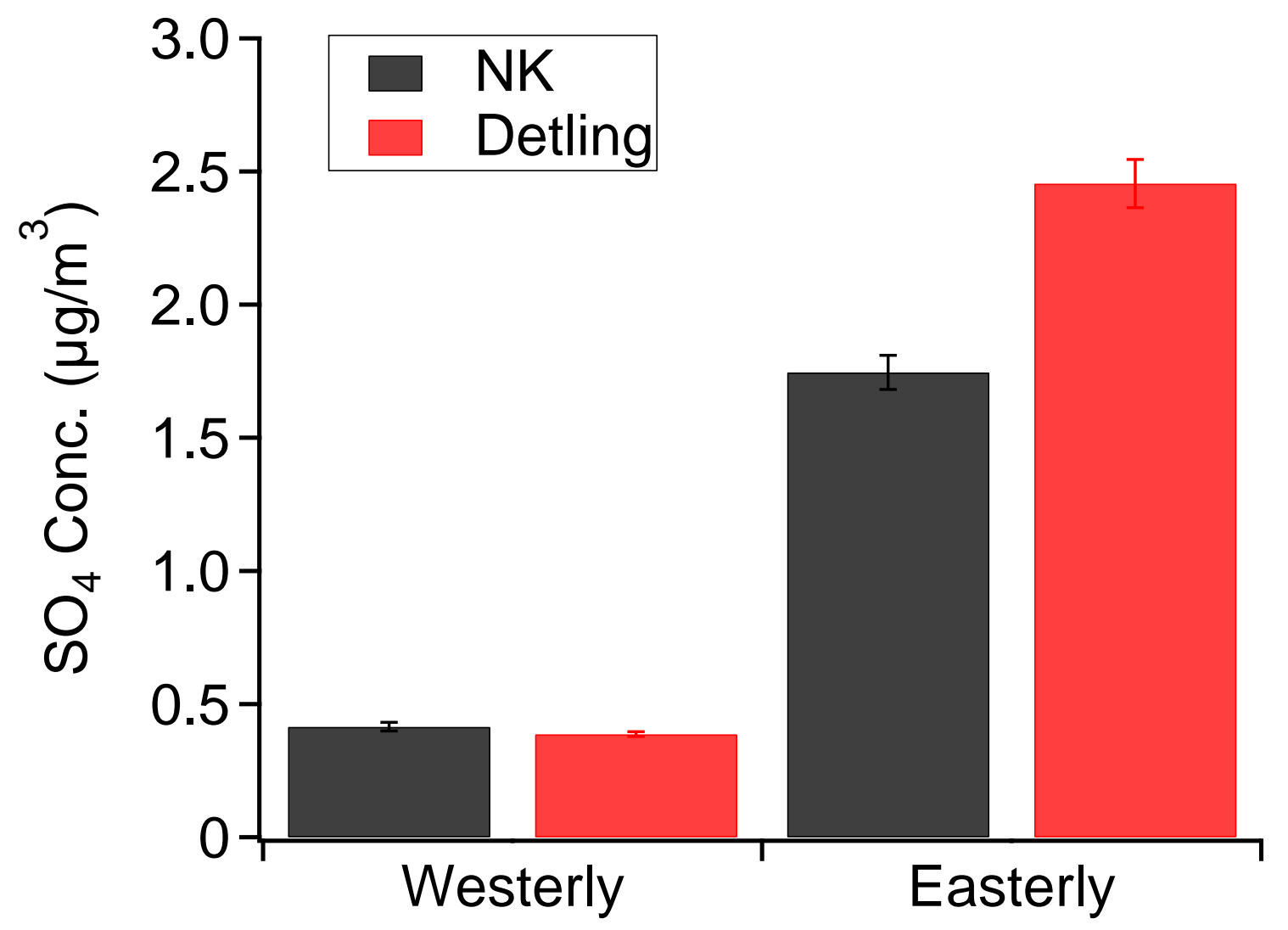


Fig. S15

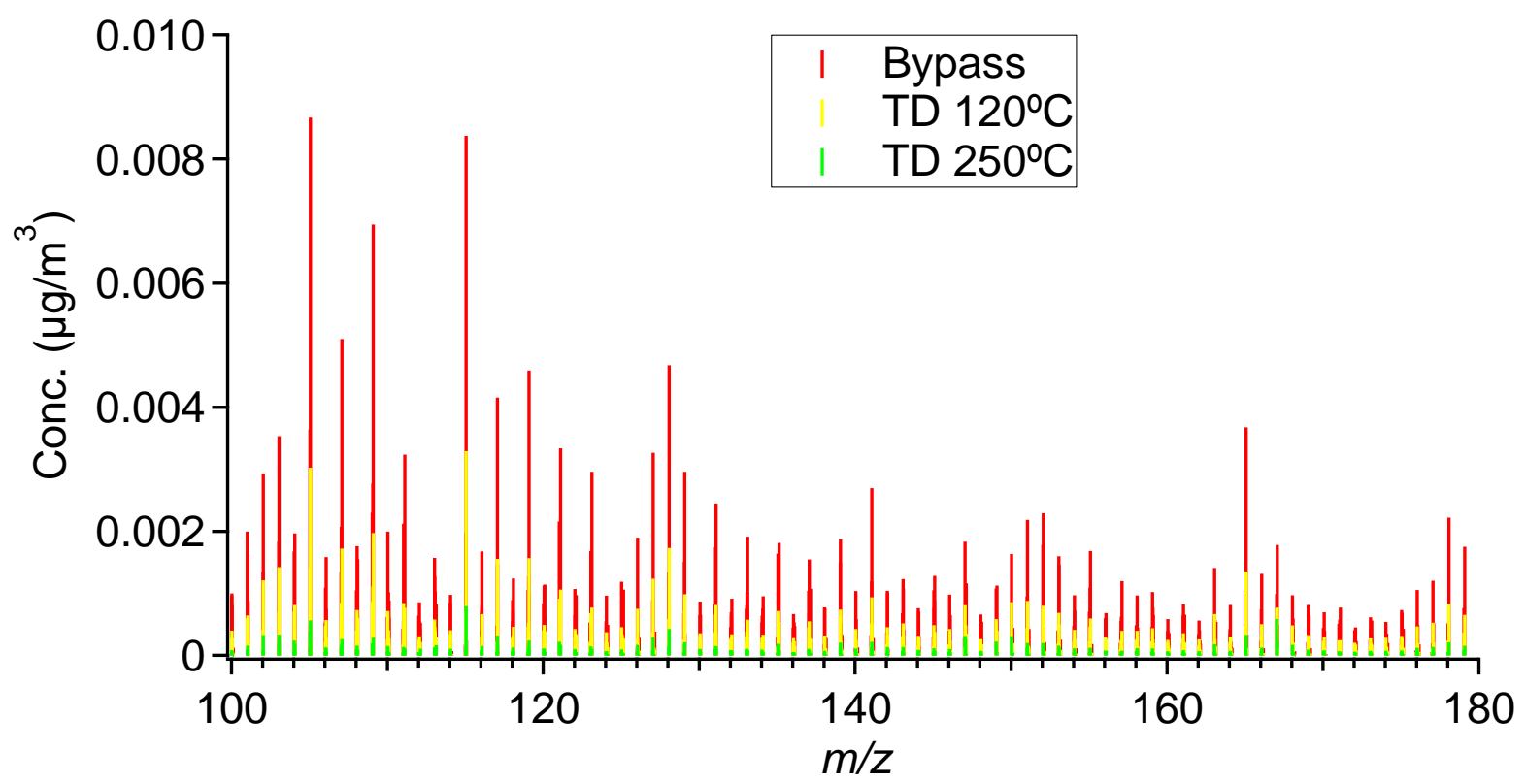


Fig. S16

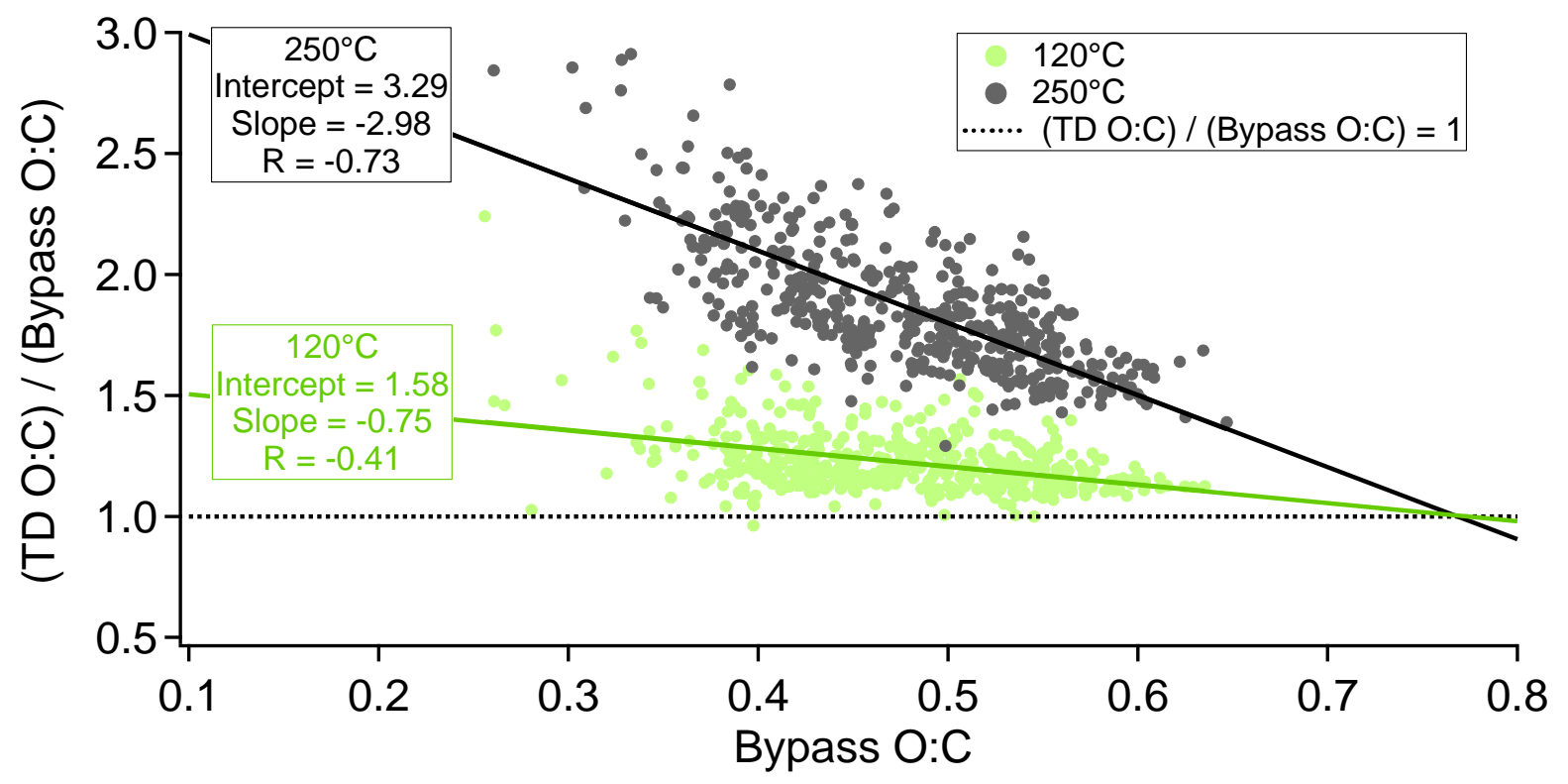


Table S1

\begin{tabular}{|c|c|c|c|c|c|c|c|}
\hline \multirow{2}{*}{ method } & rBC density & \multicolumn{2}{|c|}{ bypass } & \multicolumn{2}{c|}{$120^{\circ} \mathrm{C}$} & \multicolumn{2}{c|}{$250^{\circ} \mathrm{C}$} \\
\cline { 3 - 8 } & $\left(\mathrm{g} / \mathrm{cm}^{3}\right)$ & avg & std & avg & std & avg & std \\
\hline CDCE & $--^{\mathrm{a}}$ & 0.52 & 0.08 & 0.53 & 0.07 & $\mathrm{n} / \mathrm{a}^{\mathrm{b}}$ & $\mathrm{n} / \mathrm{a}^{\mathrm{b}}$ \\
\hline \multirow{4}{*}{$\begin{array}{c}\text { SMPS- } \\
\text { CE }\end{array}$} & 1.77 & 0.57 & 0.10 & 0.42 & 0.07 & 0.21 & 0.10 \\
\cline { 2 - 8 } & 1.00 & 0.59 & 0.10 & 0.44 & 0.07 & 0.26 & 0.13 \\
\cline { 2 - 8 } & 0.80 & 0.60 & 0.10 & 0.46 & 0.07 & 0.31 & 0.16 \\
\cline { 2 - 8 } & 0.73 & 0.60 & 0.10 & 0.47 & 0.07 & 0.36 & 0.15 \\
\cline { 2 - 8 } & 0.60 & 0.62 & 0.10 & 0.49 & 0.07 & 0.47 & 0.47 \\
\hline
\end{tabular}

${ }^{a} \mathrm{rBC}$ density is not required for the CDCE method.

${ }^{\mathrm{b}} \mathrm{CDCE}$ for TD $250^{\circ} \mathrm{C}$ is not available due to the low concentration of ammonium after heating at $250^{\circ} \mathrm{C}$. 